\title{
Comparative Study of 440 Gene Expression of Mycoplasma Agalactiae Isolated from Iranian Provinces
}

\author{
Fereshteh Yavari ${ }^{1}$, Seyed Ali Pourbakhsh ${ }^{2}$, Hossein Goudarzi ${ }^{2}$ \& Ramezan Ali Khavarinejad ${ }^{1}$ \\ ${ }^{1}$ Department of biology, Science and Research branch, Islamic Azad University, Tehran, Iran \\ ${ }^{2}$ Mycoplasma Reference Laboratory, Razi Vaccine\& Serum Research Institute, Karaj, Iran \\ Correspondence: Seyed Ali Pourbakhsh, Mycoplasma Reference Laboratory, Razi Vaccine\& Serum Research \\ Institute, Karaj, Iran. E-mail: a.pourbakhsh@chmail.ir
}

Received: November 30, 2017

Accepted: January 2, 2018

Online Published: July 11, 2018

doi:10.5539/jmbr.v8n1p61

URL: https://doi.org/10.5539/jmbr.v8n1p61

\begin{abstract}
Mycoplasma agalactiae pathogen is the main cause of agalactia in small ruminants and as such, results in some economic losses in Iran. Contagious agalactia disease should be regarded as a syndrome, caused by various Mycoplasmas which infect several organs. In the present study, 30 suspected samples from 11 provinces of Iran were isolated from mammary gland, joint and eyes of sheep and goats and subjected to genus and species detection via PCR technique for 2 genes. These Mycoplasma strains and three Iranian vaccinal strains of Mycoplasma agalactiae were submitted to sequence analysis of a surface lipoprotein called $p 40$ protein. Based on a comparative study between Iranian strains and PG2 Spanish strain of Mycoplasma agalactiae, most Iranian strains presented $97 \%$ homology, whereas some strains showed $80-88 \%$ and three vaccinal strains were associated with $99 \%$ homology. According to PCR and bioinformatics analysis outcomes, 6 provinces of Iran were recognized as infection areas with different expressions of this effecter protein, suggesting that finding the individual characteristics of a particular effecter may require empirical testing for vaccination. Finally, the selected sequence of 40 gene was cloned into pGEMB1cloning vector and subsequently expressed in Escherichia coli by pET-22b+ expression plasmid under the control of the T7 promoter. The expression of this fusion protein was absorbed and confirmed by SDS-PAGE. The recombinant P40 protein was expressed with a molecular mass of $37 \mathrm{kDa}$ on SDSPAGE. The sera taken from rabbits infected with Mycoplasma agalactiae produced polyclonal antibody which was then used for westernblotting. The rabbits were bled 10 days after the booster immunization using cardiac puncture. Significantly, the use of recombinant specific antigens instead of other tools for diagnosis of a disease could improve the discrimination and separation of positive and negative animals in the area under investigation and therefore, it can be applied to control infected animals and reduce economic losses.
\end{abstract}

Keywords: P40 lipoprotein, Mycoplasma agalactiae, gene expression, Iranian isolate, western blot, polyclonal antibod.

\section{Introduction}

Mycoplasma agalactiae is the cause of small ruminant syndrome that infects he main target organs of animals, including mammary glands, joints, respiratory system and eyes (Bergonier and Berthelo,1997). Agalactia, which is induced by other mastitis-causing Mollicutes like Mycoplasma putrefaciens, Mycoplasma mycoides and Mycoplasma capricolum (Nouvel, 2010), has been reported in the Mediterranean countries of Asia Minor like Iran, Iraq, the United Arab Emirates, Afghanistan and Pakistan with serious economic losses in shepherding due to the reduction in milk, cheese production and also mortality of lambs. Although Contagious agalactia has been observed in different continents, the major foci of stable and long-standing infection in goats has been found in Iran, Spain, Switzerland, Iraq, France and Italy (Bergonier and Berthelo, 1997). While the serological response to Mycoplasma agalactiae has been detected through various strategies such as growth inhibition test, ELISA and immunoblotting (Fusco and Coronal, 2007), these protocols need a proper knowledge of surface proteins of this pathogen. Many surface lipoproteins including P30, P40, P80, P55, Vpma, P48, etc. which have been found in Mycoplasma agalactiae, are able to switch their gene expression during immune evasion and adherence to epithelium cells underc host physiologic conditions (Nouvel, 2009). Genomic and proteomic analyses have provided powerful immunological insights into a few proteins of this pathogen (including P40, Vpma and P48) as suitable agents for determination kits or detection reports. Surface lipoproteins of Mycoplasma agalactiae play 
roles in infection, pathogenicity, virulence, and host-cell interactions and exhibit phase variation with high frequency in the membrane of organism (Pepin, 2003).

As $\mathrm{P} 40$ protein is expressed among different Mycoplasma agalactiae strains, except for serotype $\mathrm{C}$ strain, a suitable diagnosis test should be based on the immunodominant adhesion, for example P40 which is both immunogenic and expressed during infection in most field isolates (Fleury et al., 2002).

Different Mycoplasma agalactiae strains exhibit different and variable expression levels of P40 protein. This protein is not continuously expressed, indeed it is only expressed in the chronic phase of infection. Floury et al. (2002) have performed a detailed molecular study on P40 protein to characterize its role in host-cell interaction, analysis of the mechanisms of variation, immunological determinants and its presence in Mycoplasma strains.

In Mycoplasma agalactiae, the lipoprotein structure has been shown to be located on the external surface of cell. Fleury et al. (2001) conducted genetic, functional and cloned immunodominant protein P40 analyses on Mycoplasma agalactiae, based on phage library. Although the amino acid sequence of $\mathrm{P} 40$ was similar among P40 protein of this pathogen and adhesin P50 and P89 of other Mycoplasmas, the single copy gene of $p 40$ was expressed by all Mycoplasma agalactiae strains and was not present in closely related Mycoplasma species.

Mahdavi et al. have amplified the $p 40$ gene of three strains of Mycoplasma from Iranian samples and measured the homology of Iranian and French Mycoplasma agalactia estrains. Based on their results, Iranian strains are 84\% homologous to French strains (Mahdavi et al., 2009). The immune reactivity and suitability of P40 as a diagnostic antigen have been investigated in previous studies (Fleury et al., 2002). Therefore, in the present work, the selected sequence of $p 40$ gene of Mycoplasma agalactiae strains (from Iran) as a recombinant antigen was expressed in E. coli. Here, we evaluated the amplification of $p 40$ gene of strains using PCR technique and culture. After detection of this gene in the isolates of 11 Iranian provinces, we sequenced and analyzed the sequence for homology to other p40 genes in gene bank. Therefore, the selected $p 40$ gene was cloned, detected and measured in terms of its expression.

\section{Materials and Methods}

\subsection{Strain and Cultivation}

30 suspected isolates obtained from mammary gland, joint, blood and eyes of being Mycoplasma agalactiae from 11 Iranian provinces (including Kurdistan, Azerbaijan, Sharghi, Kerman, Khuzestan, Ilam, Ardebil, Ghom, Guilan, Yazd, Esfahan and Sistan \& Baluchistan) as well as three Iranian vaccinals of Mycoplasma agalactiae (From Taleghan, Shiraz, Lorestan) were received and cultured until mid-exponential phase in PPLO broth containing horse serum, Penicillin and 2\% NAD. Furthermore, cultures from the initial passage of Mycoplasma agalactiae strains of 11 Iranian provinces were cultured on PPLO agar at $37 \mathrm{C}^{\circ}$ for 1 week to examine the presence of Mycoplasma colonies (kheirkhah et al., 2011).

\subsection{DNA Extraction}

Mycoplasma agalactiae cells were harvested through centrifugation at $13000 \mathrm{rpm}$ for 5 min followed by suspension in $200 \mu \mathrm{l}$ of lysis buffer. The tubes were incubated at $56^{\circ} \mathrm{C}$ for $4 \mathrm{~h}$ and centrifuged at $13000 \mathrm{rpm}$ for 15 min. DNA extraction was initiated by adding an equal volume of phenol chloroform to microtubes and centrifugation aspreviously described. After centrifugation, the total DNA, which was the upper most phase in each microtube, was transferred into a new microtube. Mycoplasma genomic DNA was prepared and observed in $2 \%$ agarose using electrophoresis technique. These isolated genomes were washed in TE buffer and stored at $4{ }^{\circ} \mathrm{C}$ in the same buffer until digestion step (kheirkhah et al., 2011).

\subsection{Determination of Mycoplasma agalactiae}

The genus and species Mycoplasma agalactiae were detected using PCR (Glew, 2000). Briefly, the oligonucleotide primers: 5'GCTGCGGTGAATACGTTCT3' (forward) and 5'TCCCCACGTTCTCGTAGGG 3' (reverse) were used for PCR technique to amplify the 16s $r R N A$ gene for genus detection.

All received isolates including vaccinal and field strains were confirmed to belong to the species Mycoplasma agalactiae. For this target, two primers were used (FS1: 5'AAAGGTGCTTGAGAAATGGC3' and FS2:5'GTTGCAGAAGAAAGTCCAATCA 3') to amplify 375bp fragments of lipoprotein gene of Mycoplasma agalactiae. PCR was performed in 25 cycles and PCR reaction contained $2.5 \mu 1$ of PCR buffer, $2 \mu 1$ of $1.5 \mathrm{mM}$ $\mathrm{MgCl} 2,15 \mathrm{nmol}$ of the mix dNTPs, 75 pmol of each of the two primers, $10 \mathrm{ng}$ of genomic DNA, and 1.5 units of Taq enzyme in a total volume of $25 \mathrm{ml}$ (kheirkhah et al., 2011). 


\subsection{Detection of the p40 Gene from Mycoplasma agalactiae Strains}

Detection of the $p 40$ gene of Mycoplasma agalactia was performed using PCR technique with two oligonucleotide primer pairs, namely MAR and MAf with the following sequences:

\section{MAF: 3'TGATGATAAGAACGAAAATTCAC5'}

\section{MAR: 3'ACCAGTGTCTTTTGATTTAAC5.'}

A final volume of $25 \mu \mathrm{L}$ (containing $10 \mathrm{x}$ PCR buffer, $2 \mathrm{mM} \mathrm{MgCl} 2,10 \mu \mathrm{M}$ deoxynucleoside triphosphate (dNTP), $14 \mathrm{nM}$ concentrations of primers, $5 \mathrm{U}$ of enzyme and $7 \mathrm{ng}$ of genomic DNA as a template) was used for the experiment. Taq DNA Polymerase was used with the following amplification program: a predenature step at $94^{\circ} \mathrm{C}$, 35 cycles including denature step at $94{ }^{\circ} \mathrm{C}$ for $30 \mathrm{sec}$, annealing at $52.5^{\circ \mathrm{C}}$ for $30 \mathrm{sec}$, polymerization at $72{ }^{\circ} \mathrm{C}$ for 1 min and extension step at $72^{\circ} \mathrm{C}$ for 7 min (kheirkhah et al., 2011). Gel elution was performed by a Sigma kit and the PCR products were sent to Bioneer Company for sequencing.

\subsection{Designing of 40 Gene for Cloning}

To determinate the genetic differences between Iranian field and vaccinal Mycoplasma agalactia strains and PG2 strain of Spain in the gene bank of NCBI, a comparative study of these DNA sequences was performed using mega5 (Center for Evolutionary Medicine and Informatics) and DNAsis MAX software (hitachi software engineering co). The selected $p 40$ gene was synthesized by Bioneer company and cloned into pGEMB1 plasmid.

\subsection{Cloning and Restriction Endonuclease Digestion}

The cloning plasmid was amplified through transformation into E. coli BL21 (DE3) pLysE. To construct a plasmid encoding $p 40$ gene, pGEMB1 plasmid was digested by EcoRI enzyme and the separated gene was absorbed on agarose gel through electrophoresis. Isolation of the fraction obtained from digestion was carried out using suitable Sigma kits. The resulting double-stranded 1092-bp gene which contained EcoRI and NotI overhangs was ligated into EcoRI and NotI sites of pET-22b1 usingT4 ligase to obtain an expression vector including recombinant $p 40$ gene of Mycoplasma agalactiae (Fleury et al., 2002).

\subsection{Analysis of Ligation}

The construct was screened using PCR and restriction enzyme digestion techniques. In the PCR method, previous primers were used to detect the presence of $p 40$ gene. For double digests, after application of the first enzyme (EcoRI), it was inactivated through heating at $65^{\circ} \mathrm{C}$ for $25 \mathrm{~min}$. Thereafter, the second enzyme (NotI) cut the other side of $p 40$ gene. In addition, the recombination products derived from pET-22b1 plasmid were applied to a $2 \%$ agarose gel. On the other hand, the ligation mixture (with a plasmid: gene fragment ratio of 1:3) was run on the agarose gel and then transformed into E. coli BL21 (Fleury et al. 2002).

\subsection{Expression and Purificationofpolyhistidine-Tailed Fusion Protein P40}

The production of fusion protein was induced by the addition of $1 \%$ glucose and different amounts $(0.3,0.5,0.7$ and $1 \mathrm{mM}$ ) of isopropyl-b-D-thiogalactopyranoside (IPTG) at the mid-exponential phase at $37^{\circ} \mathrm{C}$ for $1,2,3,4$ and $16 \mathrm{~h}$. Following centrifugation at 3,000 g for $15 \mathrm{~min}$, the resulting pellets were resuspended in the sample buffer and gently vortexed. These suspensions were stored at $-20{ }^{\circ} \mathrm{C}$ for subsequent application in SDS-PAGE and western blotting experiments (Fleury et al. 2002).

Osmotic shock was applied according to the following steps: 1. Cells were exposed to a solution containing 30 $\mathrm{mM}$ Tris, $20 \%(\mathrm{w} / \mathrm{v})$ sucrose, $1 \mathrm{mM}$ EDTA with a $\mathrm{pH}$ of 8 , followed by incubation at $4^{\circ \mathrm{C}}$ for $30 \mathrm{~min}$. 2 . The pellet containing membrane fraction from sucrose treated cells was rapidly dispersed in cold $5 \mathrm{M} \mathrm{MgCl}_{2}$ and collected by centrifugation at $3000 \mathrm{rpm}$ for $15 \mathrm{~min}$. The supernatant (cytosolic fluid of cells) and pellet were stored on ice for $12 \%$ SDS-PAGE analysis (Fleury et al. 2002).

\subsection{Production of Polyclonal Antibody}

\subsubsection{Injection of Mycoplasma agalactiae into Rabbits}

Mycoplasma agalactiae, as the antigen, was cultured in $1000 \mathrm{ml}$ of PPLO broth and Phenol red-free solid media. The bacterial cells were harvested after $24 \mathrm{~h}$.

Broth medium was centrifuged at $30000 \mathrm{rpm}$ for $45 \mathrm{~min}$. The supernatant fluid was discarded and the sediment pellet was washed and vortex twice in phosphate-buffered saline (PBS).

It was essential to resuspend the pellet in the washing fluid each time to ensure adequate washing. The pellet was resuspended in $8 \mathrm{ml}$ of PBS. $4 \mathrm{ml}$ of Freund's complete adjuvant was emulsified with an equal quantity of antigen suspension (Clyd, 1964). 
The emulsified antigen was used for immediate injection of animals. Any remaining antigen was stored in aqueous phase at -70 for application in the booster injection. Each rabbit was pre-bled so as to obtainapproximately $10 \mathrm{ml}$ of blood, such that a sample of pre-immunization serum could be achieved. 4 rabbits were immunized. On day 0:0.5 ml intramuscular and $0.2 \mathrm{ml}$ intradermal injections into each of 4 sites on each rabbit. On day 21:0.5 ml of booster was injected into each of the four intramuscular sites on each rabbit. The blood test was performed on days 28,35 and 42 (Clyd, 1964).

\subsubsection{Growth Inhibition Test}

Filter paper disks were soaked in antisera and placed on lawn of organisms seeded on agar plate. An inhibitory zone of 5-15 mm around the disks with undiluted antisera showed satisfactory results for immuneblotting test (Clyd, 1964).

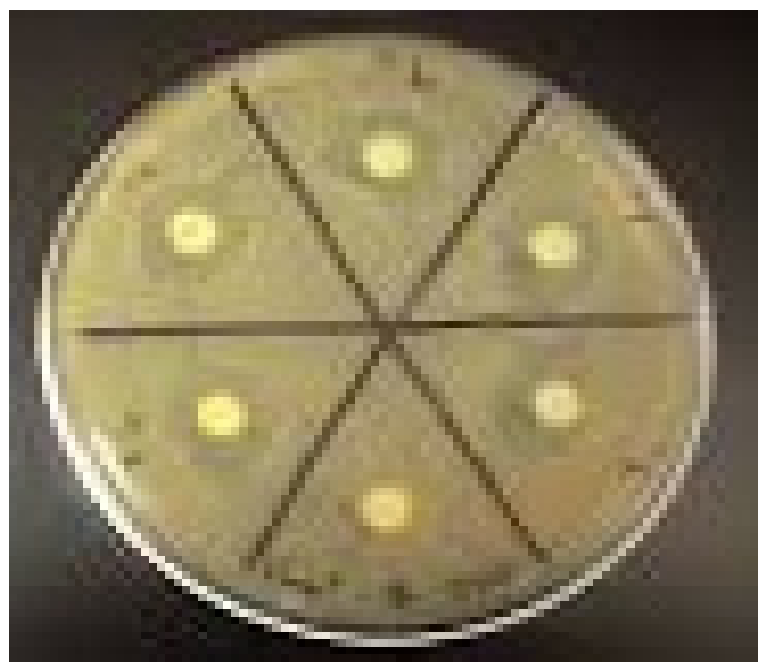

Figure $1.5 \mathrm{~mm}$ zone antibody around the Mycoplasma agalactiae untisera disk

\subsubsection{Antiserum Preparation}

Rabbits were bled 10 days after the booster immunization using cardiac puncture. Antisera were prepared from the $50 \mathrm{ml}$ blood samples. After incubation of the samples at $37^{\circ} \mathrm{C}$ for $24 \mathrm{~h}$ without any movement, they were centrifuged at $1000 \mathrm{rpm}$ for $5 \mathrm{~min}$ and stored at $-20^{\circ} \mathrm{C}$ (Clyd, 1964).

\subsubsection{Immunoblotting}

The total antigen from recombinant E. coli was mixed with equal volume of sample buffer. Samples were boiled for $5 \mathrm{~min}$ and then, to identify antigenic proteins, components of extracted E. coli proteins were separated on $12 \%$ polyacrylamide gels and blotted onto nitrocellulose membranes with rabbit antiserum at a dilution of 1:100. The membranes were blocked with 5\% milk buffer for $24 \mathrm{~h}$ at room temperature and then incubated with the first antibody at a dilution of $1: 100$. The membranes were washed with $1 \%$ PBS and experimental serials were incubated with polyclonal anti-rabbit peroxidase-labeled antibody with shaking at a dilution of $1: 50$ at $37^{\circ} \mathrm{C}$ for 30 min (Fleury, 2002).

\section{Results}

\subsection{Bacterial Strains and Culture}

The late logarithmic phase of growth for 30 field strains and three vaccinal strains from Mycoplasma agalactiae were positive. For egg fried colony growth detection of Mycoplasma, petri dishes were analyzed using a microscope. Based on PCR results, infection was observed in the sheep and goat species of 6 provinces including Kurdistan, Yazd, Khuzestan, Ilam, Ardebil and Esfahan.

\subsection{Identification of Mycoplasma agalactiae}

The genus Mycoplasma was detected through amplification of the $163 \mathrm{bp}$ fragment of $16 \mathrm{~S} r R N A$ gene of bacterial cell. According to the results, all strains belonged to the Mycoplasma genus. On the other hand, the presence of fragments with 375 bp length showed that among 30 field strains of Mycoplasma, 16 field strains and three vaccinal 
strains were Mycoplasma agalactiae type. In other words, these strains contained the specific lipoproteins of agalactia species. To assess the species specificity of $\mathrm{P} 40$ protein, the results were confirmed by two primers which amplified the $920 \mathrm{bp}$ fragment of $p 40$ gene from the genome of Mycoplasma agalactiae strains. Some strains have been shown in Figure 2.

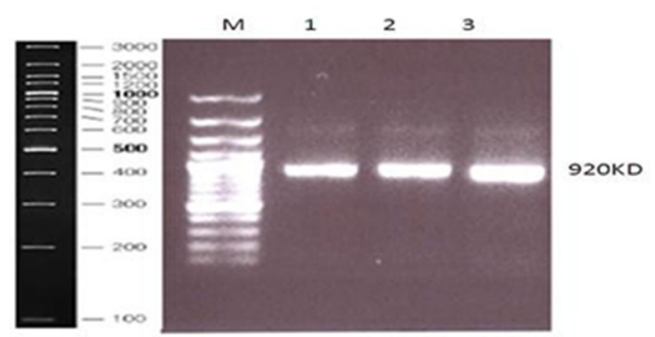

Figure 2. $920 \mathrm{bp}$ fragments of P40 proteins: marker 1: Lorestan vaccinal strain. 2: Kurdistan field strain. 3: Kerman field strain

\subsection{Cloning the Gene for a P40 Antigen of Mycoplasma agalactiae}

19 received sequence results were compared with $p 40$ gene sequence of PG2 strain of Spanish data bases using a BLAST DNAsis MAX software. The highest variation was observed among 3' and 5' terminate sequences of $p 40$ gene. On the other hand, $920 \mathrm{bp}$ fragments of the $p 40$ gene were analyzed using mega5 software. Most Iranian strains, including Kurdistan, Yazd, Khuzestan and Ilam presented 97\% homology, whereas some strains such as Esfahan and Ardebil showed 80-88\% homology and three vaccinal strains were associated with $99 \%$ homology. A mature $p 40$ gene sequence based on Iranian vaccinal strains which was designed and synthesized by Bioneer company and cloned into pGEMB1plasmid, was partially digested by EcoRI and hence, the $p 40$ gene fragment exited. The results of $p 40$ gene cloning was detected via electrophoresis technique. After digestion of recombinant plasmid including $p 40$ gene with two enzymes, a 1080 bp fragment was observed in $2 \%$ agarose gel.

\subsection{Detection of Recombinant fusion P40 Protein}

SDS-PAGE was used as a semiquantitative parameter for comparing the expression of the P40 protein among different IPTG concentration of Iranian isolates. The highest expression level among four tube for each Iranian isolate was assessed by $0.5 \mathrm{mM}$ of IPTG (Figur 3).

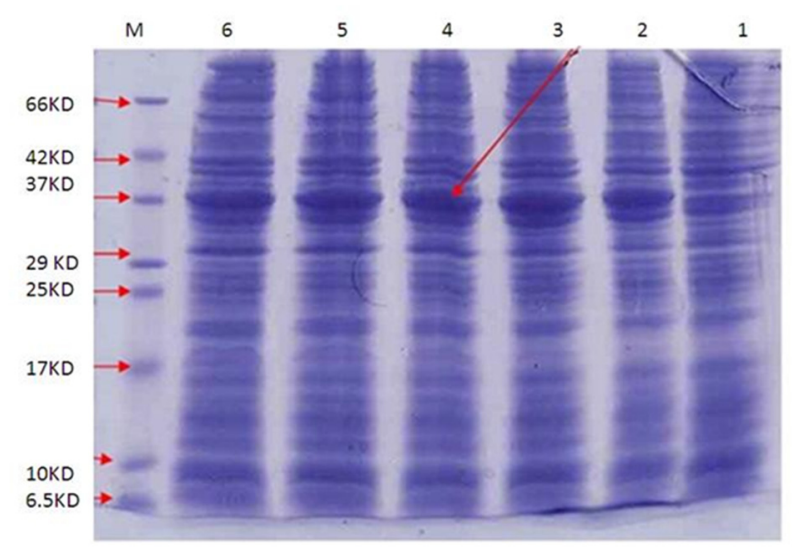

Figure 3. SDS-PAGE of p40 protein from recombinant cell. Lane m: marker. Lane 1: control without IPTG induction. Lane $2.1 \mathrm{~h}$ after induction. Lane $3.2 \mathrm{~h}$ after induction. lane $4.3 \mathrm{~h}$ after induction. lane $5.4 \mathrm{~h}$ after induction. $6.16 \mathrm{~h}$ after induction 
Because of PelB signal (for protein targeting into perplasmic space) in expression vector, fusion protein was targeted into this location of bacterial cell. The SDS-PAGE results of supernatant and pellet of cell lyses via osmotic shock implied that the P40 protein with $37 \mathrm{KD}$ was found in pellet including membrane debris.

To confirm the presence of immunodominant P40 protein, immune blot test of SDS-PAGE was carried out using polyclonal antibody which was migrated on nitrocellulose membrane to react with one bond of protein with 37 KD weight (Figure 4).

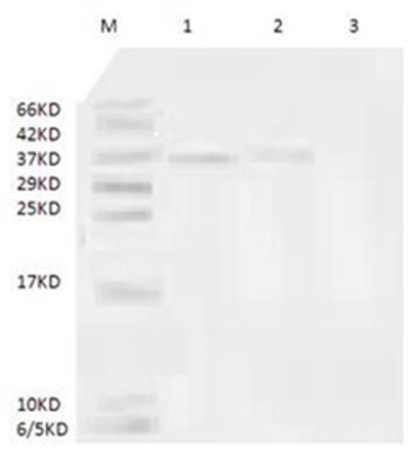

Figure 4. western blotting results of P40 protein expression. Lane m: marker. Lane 1: lorestan vaccinal strain.

Lane 2: kurdistan strain. Lane3: control

\section{Discussion}

The $p 40$ gene of Mycoplasma agalactiae was chosen for work because based on recent reports, its expression level (as an immunodominant adhesion) increases in inflammation and immune defense and it is present in all Mycoplasma agalactiae strains, implying that $p 40$ expression is specific to Mycoplasma agalactiae species. 19 samples from 11 provinces of Iran were positive for contagious agalactia infection. Although the results of antibody response to $\mathrm{P} 40$ indicated that this gene is highly immunogenic in rabbits, some $\mathrm{P} 40$ protein sequences of Iranian strains showed weak similarities with PG2 strains of Gen Bank data bases. This paper presents a comprehensive study on $p 40$ gene expression in Mycoplasma agalactiae strains of Iranian and European strains in sheep and goat infected by this bacterial cell. The results of homology analysis of $p 40$ gene sequences were indicative of small differences in sequences of these strains.

No appropriate diagnosis assay and satisfactory detection for agalactia was available in Iran. Michel Pépin has used and tested the ELISA assay based on several sera in many laboratories for serologic diagnosis of contagious agalactia. As the control, the randomly taken sera were tested twice a year for each flocks of milk. To assess and detect the Mycoplasma agalactiae antibodies, the sera collected from flocks and infected sheep were titrated using three ELISA kits (Pepin et al., 2003).

Fusco et al. have designed a new recombinant enzyme-linked immunosorbent assay based on Mycoplasma agalactiae surface proteins, namely P80 and P55. To select suitable proteins for rELISA, they performed in-depth genomic and proteomic analyses and characterizations on some stable proteins such as variable surface lipoproteins of P80, P48, and P30 with phase and size variations similar to P40. They used Polyclonal sera against P80 and P55 and produced recombinant P80 and P55 peptides (Fusco and Coronal, 2007).

Fleury et al. cloned the gene for a 30-kDa immunodominant antigen, P30, of Mycoplasma agalactiae, PG2 strain in E. coli. Mycoplasma genomic DNA was extracted and partially digested by Sau3AI and then, fragments were ligated. These DNAs were sequenced and studied byimmunoblot analysis and ELISA (Fleury et al., 2001).

Although some attempts have been made to detect agalactia for Mycoplasma agalactiae vaccination and control, other Mycoplasma species can cause agalactia, as well. P30, P48, P55 and P80 are surface proteins of Mycoplasma agalactiae, but $\mathrm{P} 40$ is the immunodominant protein and suitable for diagnostic assays like ELISA, as a sensitive assay for detection of host serum antibodies against Mycoplasma agalactiae (Nouvel, 2009).

For the first time, we selected the $p 40$ gene of Mycoplasma agalactiae from 30 provinces of Iran and three vaccinal strains from Razi institute (Karaj, Iran) for cloning and secretion analysis in E. coli. The presence of $1080 \mathrm{bp}$ fragment in the expression plasmid was indicative of a correct cloning. To complete this study, in the case of 
positive results the expression of the P40 lipoprotein was investigated in E. coli. The results of osmotic shock revealed a significant difference among the upper and pellet phases in P40 expression.

While multiple strategies for prevention and fast diagnosis of related bacterial species causing agalactia can address various issues for understanding and designing novel techniques and vaccines (like HBV surface antigen as the vaccine), P40 can be used for both diagnosis and treatment.

\section{Acknowledgments}

We thank all supports from the Mycoplasma reference laboratory, Razi Vaccine and Serum Research Institute, Karaj, Iran. This work was financially supported by of the Razi instituteand Education and Research Deputy of Jihad-Agriculture Ministry (Grant No.2-18-18-89067).

\section{References}

Bergonier, D., Berthelot, X., \& Poumarat, F. (1997). Contagious agalactia of small ruminants: current knowledge concerning epidemiology, diagnosis and control. Revue scientifique et technique (International Office of Epizootics), 16(3), 848-873.

Clyde, W. A. (1964). Mycoplasma species identification based upon growth inhibition by specific antisera. The Journal of Immunology, 92(6), 958-965.

Czurda, S., Jechlinger, W., Rosengarten, R., \& Chopra-Dewasthaly, R. (2010). Xer1-mediated site-specific DNA inversions and excisions in Mycoplasma agalactiae. Journal of bacteriology, 192(17), 4462-4473.

Fleury, B., Bergonier, D., Berthelot, X., Schlatter, Y., Frey, J., \& Vilei, E. M. (2001). Characterization and analysis of a stable serotype-associated membrane protein (P30) of Mycoplasma agalactiae. Journal of clinical microbiology, 39(8), 2814-2822.

Fleury, B., Bergonier, D., Berthelot, X., Peterhans, E., Frey, J., \& Vilei, E. M. (2002). Characterization of P40, a cytadhesin of Mycoplasma agalactiae. Infection and immunity, 70(10), 5612-5621 .

Fusco, M., Corona, L., Onni, T., Marras, E., Longheu, C., Idini, G., \& Tola, S. (2007). Development of a sensitive and specific enzyme-linked immunosorbent assay based on recombinant antigens for rapid detection of antibodies against Mycoplasma agalactiae in sheep. Clinical and Vaccine Immunology, 14(4), 420-425.

Glew, M. D., Papazisi, L., Poumarat, F., Bergonier, D., Rosengarten, R., \& Citti, C. (2000). Characterization of a multigene family undergoing high-frequency DNA rearrangements and coding for abundant variable surface proteins in Mycoplasma agalactiae. Infection and immunity, 68(8), 4539-4548.

Kheirkhah, B., Pourbakhsh, S. A., Ashtari, A., \& Amini, K. (2011). Detection of Mycoplasma agalactiae by culture and Polymerase Chain Reaction (PCR) methods from affected sheep to contagious agalactiae in Baft County.

Mahdavi, S., Salehi, T. Z., Madani, R., \& Keyvanfar, H. (2009). Comparative study of homology of cytoplasmic membrane protein $40 \mathrm{KDa}$ of Mycoplasma agalactiae in isolated strains in Iran. African Journal of Microbiology Research, 3(9), 528-532.

Nouvel, L. X., Marenda, M., Sirand-Pugnet, P., Sagné, E., Glew, M., Mangenot, S., ... \& Citti, C. (2009). Occurrence, plasticity, and evolution of the vpma gene family, a genetic system devoted to high-frequency surface variation in Mycoplasma agalactiae. Journal of bacteriology, 191(13), 4111-4121.

Nouvel, L. X., Sirand-Pugnet, P., Marenda, M. S., Sagné, E., Barbe, V., Mangenot, S., ... \& Blanchard, A. (2010). Comparative genomic and proteomic analyses of two Mycoplasma agalactiae strains: clues to the macro-and micro-events that are shaping mycoplasma diversity. BMC genomics, 11(1), 86.

Pépin, M., Dufour, P., Lambert, M., Aubert, M., Valognes, A., Rotis, T., ... \& Bergonier, D. (2003). Comparison of three enzyme-linked immunosorbent assays for serologic diagnosis of contagious agalactia in sheep. Journal of veterinary diagnostic investigation, 15(3), 281-285.

Strong, E. K. Jr., \& Uhrbrock, R. S. (1923). Bibliography on job analysis. In L. Outhwaite (Series Ed.), Personnel Research Series: Vol. 1. Job analysis and the curriculum (pp. 140-146). http://dx.doi.org/10.1037/10762-000

\section{Copyrights}

Copyright for this article is retained by the author(s), with first publication rights granted to the journal.

This is an open-access article distributed under the terms and conditions of the Creative Commons Attribution license (http://creativecommons.org/licenses/by/4.0/). 